\title{
Experts want Big Tobacco on trial
}

1

coalition of public health and legal experts is urging provincial governments not to settle ongoing battles with tobacco companies out of court, arguing that a greater good would be served by exposing the inner workings of the industry.

Nine provinces have filed lawsuits against Canadian tobacco manufacturers to recover the publicly funded health costs of treating tobacco-related disease. Claims filed to date exceed $\$ 110$ billion. The provinces allege that the companies involved lied for decades about tobacco risks, nicotine addiction, second-hand smoke and targeting youth.

"This industry has consistently and deliberately pushed the limits of what's socially and legally acceptable...to promote its products," says Dr. Richard Schabas, former Ontario chief medical officer of health. He's joined more than 130 other prominent Canadians and health organizations, including medical officers for 18 of Canada's largest cities, in the Campaign for Justice on Tobacco Fraud. "Ultimately, this isn't about money; it's about winning the battle for the health of Canadians and exposing who the enemy is in that battle."

In a June 17 open letter, the campaign warned that "manufacturers will not negotiate in a meaningful way unless attorneys general in Canada prepare both to go to trial and, preferably, take the manufacturers through trial."

Without a trial, "the industry will demand that the provinces make huge concessions in order to obtain a settlement," they state, citing the "tragic missed opportunities" of tobacco smuggling settlements negotiated by the federal government and industry in 2008 and 2010.

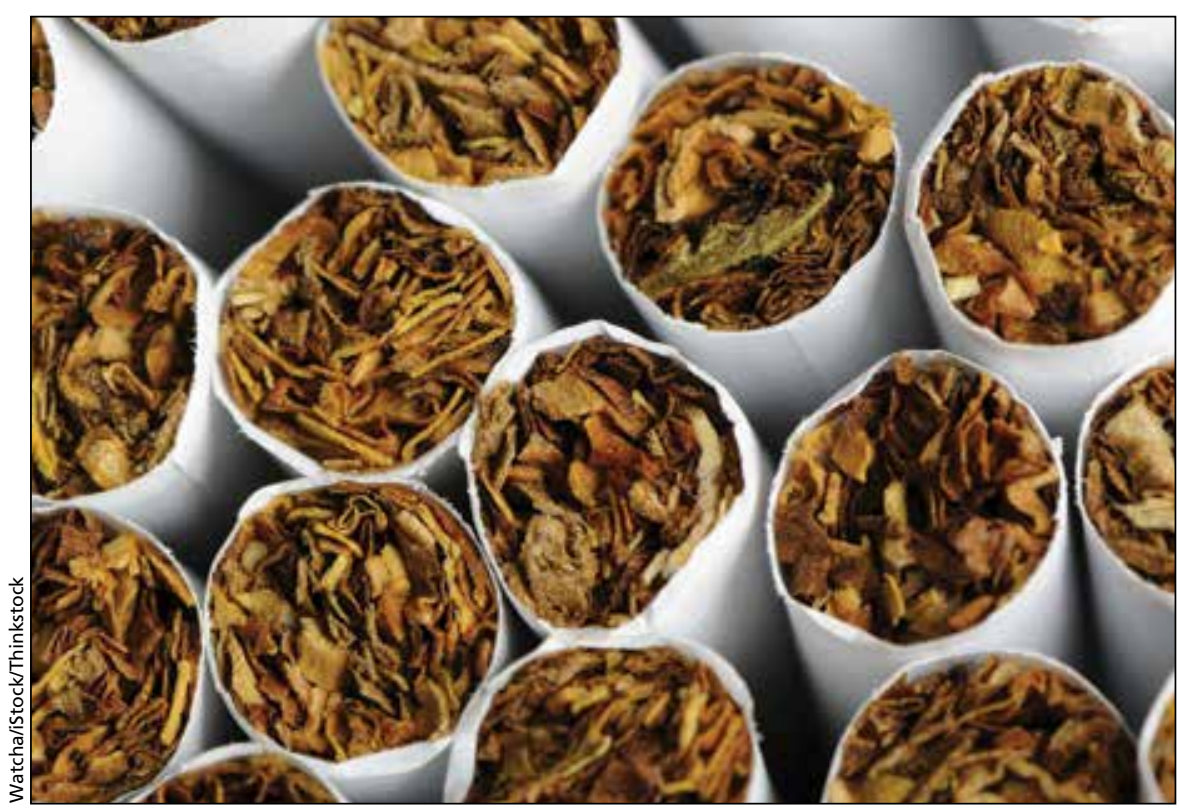

Some 130 prominent Canadians and health organizations are pressing the provinces to put public health first in legal fights with the tobacco industry.

Criminal investigations and civil lawsuits in Canada have resulted in "settlements for pennies on the dollars claimed, no disclosure of industry documents and no real incentive for the manufacturers to change their behaviour," said Robert Solomon, a law professor at Western University in London, Ontario, in a press release.

According to Garfield Mahood, president of the Campaign for Justice on Tobacco Fraud, the public disclosure in the United States of more than 40 million pages of industry documents remains one of the great achievements in tobacco control of the last century.

Similar disclosures in Canada are "absolutely critical" to "reveal to the public and legislators how badly the industry was and is behaving, and advance public policy, law reform and regulatory initiatives," he says.
The campaign also calls on provinces to use the court awards or settlements to establish an arms-length trust to implement tobacco-control campaigns that are free from industry or political interference. Historically, those monies have gone back into general revenue, rather than being earmarked for health care or tobacco control.

Signatories to the campaign include former federal minister of health Mary Collins and the heads of national and provincial health agencies, professions and charities, including the Canadian Public Health Association, Canadian Nurses Association, Canadian Cancer Society, Heart and Stroke Foundation, and Canadian Union of Public Employees. - Lauren Vogel, CMAJ

CMAJ 2014. DOI:10.1503/cmaj.109-4841 